\title{
Challenges faced by Hearing Impaired pupils in learning: A case study of King George VI Memorial School
}

\author{
Mr John Mpofu and Mr Sylod Chimhenga
}

\begin{abstract}
Students with Hearing Impairment (HI) are experiencing challenges in most learning institutions of Zimbabwe. Most schools that enroll them in the majority of cases do not cater for their special needs. Some of their challenges are not dictated until too late as a result the hearing losses in these pupils become a hindrance to their learning process. This research article attempts to highlight the challenges faced by pupils with hearing loss and to suggest how best teachers can handle this challenge. The research will use a descriptive case study method to extract information from students with HI and discuss through focus group discussions the challenges the teachers grapple with when teaching pupils with hearing loss. We will discuss ways and solutions on how to develop effective learning strategies that teachers at King George IX Memorial can use in order to empower these pupils. Focus group discussions and Interviews of students with HI, and teachers were used to collect data. There are a number of instructional aides teachers can use when teaching deaf or hard of hearing students. A teacher can use sign, finger spelling and speech reading. Equipment, including overhead projectors, bulletin boards, computers and televisions showing captions on the screen, can also be used in teaching.
\end{abstract}

Accepted Date: 01 June 2013

\section{Introduction}

King George VI Memorial School was established in Bulawayo in 1945 with the aim of providing inclusive education to all students including pupils with challenges such as hearing impaired, the disabled as well as those that are not given opportunity to learn in a normal school set up. Some of the challenges facing such students is that they require a lot of funding in order to equip the school with appropriate training equipment especially when teaching practical lessons that include Food Preparation. Some hearing-impaired students will have enough residual hearing so that amplification through hearing aids, earphones, public address systems, or personal FM transmitter/receiver units will allow participation. It is always best to discuss with the student the requirements of a class and to determine if there are ways that the materials can be modified so that the student can participate in what may become an exciting learning experience for all concerned.

\section{Literature Review}

Lindsay (2007) is of the view that inclusive education is the main objective for the education of special need children and adolescents. It stresses the participation of special needs students in communities, culture, and curricula of local schools discouraging all forms of exclusion. The implication is that inclusive education supposes that students with different challenges are provided with specialized education in age appropriate regular classes in local schools according to their special educational needs (Forman 2002). Teachers who teach special needs students require special consideration to adjust to students' disabilities. Scholars are agreed that students with hearing loss lag behind in academic achievement as compared to their counter parts with visual impairment. The problems they face take a more severe form when these students with hearing impairment join higher classes.

\section{Impact of Hearing Impairment}

One of the major tools that a teacher can use is to attract the attention of the hearing-impaired student before speaking with a cue such as a tap on the shoulder or wave. There is need to face the person while talking (try to avoid facing the chalkboard while speaking). There is need for the teacher to speak clearly and naturally without exaggerating lip movements or volume. There is also need to avoid standing in front of a light source like a window the glare from behind makes it difficult to read lips.

The impact of hearing impairment depends on the type, extent and timing of the hearing loss. Some students will have lost hearing over a period of time, as a result, for example, of ageing or hereditary conditions. Others may have suffered permanent hearing loss as a result of workplace noise, or have the condition tinnitus, a high-pitched ringing noise in the ear. Some will have had their hearing enhanced, though not entirely restored, with cochlea implants or hearing devices. Students with a hearing impairment may experience difficulty with certain sound frequencies and have difficulties when there is significant background noise. 
Students who were deaf from birth or as the result of illness in childhood may lip-read and/or use sign language (Auslan). A student who uses Auslan as a first language of communication may have difficulty with the grammatical and syntactical structure of English and have a limited vocabulary. Some deaf students are nonverbal while others may speak differently as they cannot hear their own voices. Deaf students and hearingimpaired students may require accommodations and assistive devices to facilitate access to education - an individual needs assessment will determine this. Accommodations may be as simple as preferential seating or as complex as wireless assistive listening devices in the classroom. (Moore 1996)

The learning processes of students with hearing impairment may be affected in the different ways. Students who have been deafened in early childhood are very different to students who have lost hearing later in life in terms of educational disadvantage. For example, their range of vocabulary may be limited which in turn may affect their reading ability. Deaf and hearing impaired students tend to be visual learners - and this is difficult in an environment where much essential information is delivered exclusively by word of mouth Oyewumi (2008). Hearing impaired students may need to use assistive technology such as FM systems to participate in class. Unfortunately most of these hearing devices are not available at King George IX memorial in Zimbabwe.

The impact of hearing impairment is clear in respect of time. Students who need information transcribed from tape must sometimes wait for a significant period of time for this to happen. This means that they may fall behind other students in the class, and confidence and self-esteem may suffer as a result. Students with hearing impairment may appear isolated in the learning environment. The possibility for social contacts and for interaction with other students is often limited, and this isolation or separateness may have an impact on learning.

Participation and interaction in tutorials may be limited. Students who cannot hear the flow and nuances of rapid verbal exchange will be at a disadvantage. Students with disabilities frequently carry emotional 'baggage' as a result of past learning failures and other 'put-downs', and this can have a long-term effect on confidence, self-esteem, and on their approach to learning. Students with hearing impairment coming straight from the school system will have been used to a structured, controlled, supportive environment, and may feel uncomfortable taking some of the learning risks associated with the relatively unstructured and unsupportive environment of university. Anxiety about performing in front of others may affect participation in tutorials, particularly for students who have associated speech impairment.

\section{Teaching Strategies}

There is a range of inclusive teaching strategies that can assist all students to learn but there are some specific strategies that are useful in teaching a group which includes students with hearing impairment. Encourage students with hearing impairment to seat themselves toward the front of the lecture theatre where they will have an unobstructed line of vision. This is particularly important if the student is using an interpreter, lip-reading, relying on visual clues or using a hearing aid which has a limited range. Hearing aids may include transmitter/receiver systems with a clip-on microphone for the lecturer. If using such a microphone it is not necessary to change your speaking or teaching style. Teachers may need to repeat clearly any questions asked by students in the lecture or class before giving a response.

Teachers are not supposed to speak when facing the blackboard. They should be aware that moustaches, beards, hands, books or microphones in front of their faces can add to the difficulties of lip-readers. Students who lip-read cannot function in darkened rooms. Teachers may need to adjust the lighting in the teaching environment. If a sign interpreter is employed, follow the hints for working with a sign interpreter. It is difficult for a student watching a signer to also take notes from an overhead or blackboard. Neither is a signer able to translate, at the same time, both your words and any information given on an overhead. It is important then that all information should be available in handout.

There is need to provide written materials to supplement all lectures, tutorials and laboratory sessions. Announcements made regarding class times, activities, field work, industry visits should be given in writing as well as verbally. Allow students to record lectures or, preferably, make copies of your lecture notes available. Flexible delivery of teaching materials via electronic media is also particularly helpful for students who have difficulty accessing information in the usual ways. For deaf students new technology and the internet in particular, can be used to bridge many gaps. Ensure that lists of the subject-specific jargon and technical terms which students will need to acquire are made available early in the course.

Any videos or films used should, where possible, be should be captioned. When this is not possible, the teacher may need to consider alternative ways for students with hearing impairment to access the information. In tutorials, assist students who lip-read by having the student sit directly opposite you and ensure, if possible, that they can see all other participants. Control the discussion so that only one person is speaking at a time. Students with hearing impairment, especially those with an associated speech disorder, may prefer to have another student present their tutorial papers. 
Language abilities are often affected by hearing impairment. Many students with hearing impairment have lower reading levels, and a limited vocabulary, particularly those deafened in childhood. Provide reading lists well before the start of a course so that students with hearing impairment can begin reading early. Consider tailoring these reading lists when necessary, and provide guidance to key texts. Allow assignments or reviews to be completed on an in-depth study of a few texts rather than a broad study of many. Do not make students overanxious about making mistakes, asking questions, getting through the work or meeting learning goals. It may be helpful for students with a hearing impairment to have an individual orientation to laboratory equipment or computers to minimize anxiety, particularly in cases where class sizes are large and where it may be difficult to see or hear the demonstrator.

In considering alternative forms of assessment, equal opportunity, not a guaranteed outcome, is the objective. You are not expected to lower standards to accommodate students with a disability but rather are required to give them a reasonable opportunity to demonstrate what they have learned. Once you have a clear picture of how the disability impacts on learning you can consider alternative assessment strategies.

When their range of vocabulary is limited, students may require the use of a thesaurus or dictionary during exams. A personal computer with spelling and grammar functions may be required. There is need to provide alternatives to those assignments which are based on interviews or questionnaires, and be flexible with assignment deadlines, particularly if students have had to wait for taped material to be transcribed. There is also need to provide extra time in examinations, particularly extra time for reading questions. Some students will prefer to have questions and instructions 'signed' to them.

\section{Statement of the problem}

The learning process involved by hearing impaired pupils is not different from other pupils. However these pupils face a number of challenges that other students do not face. Due to the hearing problem some of these students require highly specialized equipment to help them learn effectively. In this research an analysis of the challenges that pupils face when learning will be discussed. Since the majority of these pupils are deaf a language that is understood by all pupils has to be used. The complication arises when the level of deafness is not the same. How does the teacher devise a teaching methodology that caters for the needs of all pupils?

\section{Research questions}

- To what extent is language of communication a hindrance to learning?

- How competent are the pupils in reading and understanding texts?

- To what extent is sign language understood by all pupils learning?

\section{Objectives of the Study}

- To discuss the impact of teaching in English to pupils who are hearing impaired.

- To explain the difficulties faced by hearing impaired pupils in learning different subjects.

- To describe the challenges faced by hearing impaired pupils in learning the curriculum in sign language.

\section{Assumptions}

Teachers who teach hearing impaired pupils are not competent in handling sign language and teaching pupils who have limited hearing loss.

\section{Research Methodology}

The study adopted a qualitative case study design. Eighteen secondary school teachers from King George IX Memorial School that teach disabled and hearing impaired pupils were purposively selected from Bulawayo Metropolitan area where the school is based. Three group discussions were used to generate data. Discussions were recorded verbatim and then transcribed. There was a partial field analysis before the focus group discussions. Data had to be verified before major analysis. The analysis followed a grounded theory which included segmenting and arranging data according to themes and sub themes. In order to retrieve data that is rich in terms of teacher experience, gender and appropriate qualifications, and subjects taught, these factors were taken into consideration when sampling the participants involved in the study

Hearing impairment: is a technically accurate description of someone who is hard of hearing or who has no hearing ... however, many Deaf, hard of hearing and late deafened people prefer not to be called impaired. Findings Language use 
The teachers were aware that hearing impaired pupils have a problem of articulating their views through the use of language. These pupils find it difficult to develop the vocabulary of the English language since they hardly hear when other people are communicating.

Most hearing impaired pupils find very difficult to express themselves.

Most of them have not developed their vocabulary (teacher KG IX)

It is well recognized that hearing is critical to speech and language development, communication, and learning. Children with listening difficulties due to hearing loss or auditory processing problems continue to be an under identified and underserved population. The earlier hearing loss occurs in a child's life, the more serious the effects on the child's development. Similarly, the earlier the problem is identified and intervention begun, the less serious the ultimate impact. Some of the pupils at KG IX fall under this group but they learn in the same class as those with a partial hearing loss. What is critical is for teachers to identify such pupils and as far as possible individualize their learning.

There are four major ways in which hearing loss affects children. It causes delay in the development of receptive and expressive communication skills (speech and language). The language deficit causes learning problems that result in reduced academic achievement. This was highlighted by teachers who stated that it is difficult to encourage some of the pupils to contribute in a lesson. There is a tendency for them to withdraw and not participate in any activity. Communication difficulties often lead to social isolation and poor self-concept.

At times I am at loss of what to do when I ask questions and these pupils just stare at me.

(middle-aged teacher with no sign language skills $K G I X)$

One of the challenges faced by teachers at KG IX is that only two of the respondents were skilled in teaching hearing impaired pupils using sign language. Some of the subjects learnt by these pupils is taught by teachers who are used to teaching in a normal school. As a result pupils with hearing loss do not benefit from such lessons since they cannot understand what is communicated through sound. The pupils with hearing loss intimated in discussions that they did not understand the instructions given to the class by the teacher because they verbalize what they have to say and there is no one to interpret into sign language. The school has not employed any interpreter to help the pupils who have not developed normal language. As a result the unavailability of sign language interpreters was causing frustrations in students with hearing impairment.

\section{Vocabulary development}

Vocabulary develops more slowly in children who have hearing loss. Children with hearing loss learn concrete words like cat, jump, five, and red more easily than abstract words like before, after, equal to, and jealous. They also have difficulty with function words like the, an, are, and $a$. The gap between the vocabulary of children with normal hearing and those with hearing loss widens with age. Children with hearing loss do not catch up without intervention. Children with hearing loss have difficulty understanding words with multiple meanings. For example, the word bank can mean the edge of a stream or a place where we put money. Children with hearing loss comprehend and produce shorter and simpler sentences than children with normal hearing. Teachers at KG IX highlighted the dilemma they face when they ask pupils to read texts and do activities or exercises. Those with severe hearing loss fail to understand what is required.

When these pupils are asked to read material with difficult words they find it difficult to understand (FGD Comment from teacher with four years teaching experience)

Children with hearing loss often have difficulty understanding and writing complex sentences, such as those with relative clauses ("The teacher whom I have for math was sick today.") or passive voice. ("The ball was thrown by Mary.") Children with hearing loss often cannot hear word endings such as $-s$ or -ed. This leads to misunderstandings and misuse of verb tense, use of plural, non-agreement of subject and verb, and possessives. In the light of the above challenges teachers should be aware of these challenges so that they find ways of helping these pupils. The only way that teachers can do in order to help these pupils is to individualize their learning by using visuals to those who cannot learn much through auditory means.

\section{Speaking}

It is tiring to strain to listen to voices you can barely hear. It is difficult to hear when there is back ground noise (FDG comment from a student with hearing loss)

Some of the pupils highlighted the fact that they lost interest in some subjects because teachers do not attempt to learn the sign language that they understood. Children with hearing loss often cannot hear quiet speech sounds such as "s," "sh," "f," "t," and "k" and therefore do not include them in their speech.

(FGD teacher's comment, My class has a wide range of pupils with different skills. Some are unable to construct a single sentence. A few are able to construct single sentence.

Children with hearing loss may not hear their own voices when they speak. They may speak too loudly or not loud enough. They may have a speaking pitch that is too high. They may sound like they are mumbling because of poor stress, poor inflection, or poor rate of speaking. 


\section{Academic Achievement}

Children with hearing loss have difficulty with all areas of academic achievement, especially reading and mathematical concepts. Children with mild to moderate hearing losses, on average, achieve one to four grade levels lower than their peers with normal hearing, unless appropriate management occurs. Children with severe to profound hearing loss usually achieve skills no higher than the third- or fourth-grade level, unless appropriate educational intervention occurs early. The gap in academic achievement between children with normal hearing and those with hearing loss usually widens as they progress through school. The level of achievement is related to parental involvement and the quantity, quality, and timing of the support services children receive.

Where parents are supportive of their child and helps with homework the performance of such pupils are better than pupils who do not get Parental support. (FGD, Young teacher KGXI.)

\section{Social Functioning}

Children with severe to profound hearing losses often report feeling isolated, without friends, and unhappy in school, particularly when their socialization with other children with hearing loss is limited. One of the pupils who was in the FDGs stated that

\section{At times you feel the teacher has no concern for your understanding when}

they continue to teach when you have no idea what is being discussed. (Pupil KGIX)

These social problems appear to be more frequent in children with a mild or moderate hearing loss than in those with a severe to profound loss. In the light of the above observations there is need for teachers to integrate the pupils in some activities so that they tackle the problem as a group. Sometimes such an approach will help to develop friendship among the pupils.

\section{Ways of accommodating hearing impaired students}

There is need to seat hearing-impaired students where there is an unobstructed view of the teacher. This classroom reorganization will ensure that these pupils can lip read if they are trained to do so. The teacher should try to repeat comments and questions asked by other students who are not in the range of vision of the hearing-impaired student. The use of visual media especially overhead projectors or PowerPoint as much as possible is encouraged. They are effective tools that will enhance the learning process for the hearing impaired pupils. The teacher needs to prepare a brief course outline, a syllabus, and a list of learning objectives for the class ahead of time. These could be distributed to pupils at the beginning of the term so that pupils can be helped at home by parents. When the content is then covered by teacher it will be familiar territory.

Teacher should assure the conveyance to hearing-impaired students of important information like class cancellations, class relocation, assignments, and tests by stating the details in writing in a hand-out and on the chalkboard. Where pupils are allowed to hire a note taker, establish a system of getting messages to hearingimpaired students especially if a note taker or interpreter is not given advance notice of class cancellations and changes. The teacher should be prepared to reword sentences when a hearing-impaired student does not understand what is being said. Persons with hearing impairments, like most of us, are not eager to draw undue attention to themselves; therefore, they may smile in acknowledgment when in fact they have not understood. Hearing loss creates problems in the way individuals express and receive language, which in turn leads to social, communication, and educational problems. Therefore, while developing learning programs, teachers need to seriously consider the impact, both short-term and long-term, of hearing loss on a person's ability to understand spoken language.

Hearing-impaired children are academically and socially vulnerable while attending school. Educators need to collaborate with children, their families and the specialists in order to adapt programming and implement alternative forms of communications, such as sign language, lip reading, visual aids and listening devices. Older children should also have input in decisions which regard adaptations of their educational program.

There is controversy over what are the most effective methods for communication to be used by deaf or hard of hearing students. The hearing impaired has urged schools to accept manual approaches, such a sign language, over oral approaches, such a speech and lip reading. According to those defending oral approaches, the human brain can learn language by hearing it only, therefore, treatment for children with hearing loss will maximize their auditory capabilities. Manualists, on the other hand, believe that if deaf pupils are forced to communicate only through speech and lip reading, they are denied full and successful communication through sign language. An alternative approach, called "total Communication", uses sign language and auditory-oral methods simultaneously.

Teachers need to make special considerations when teaching hearing-impaired children. The consideration, which mostly involves common sense, can be sharpened through close collaboration with the student, the student's family and people that have more experience and training. The student and his or her family can also offer the teacher support through constructive criticism of what is or is not working for the child in the classroom. 
When teaching hearing-impaired children, teachers should ensure that the hearing and listening environment in the classroom is optimal for the child. There should also be minimal distance between the teacher and the child so that lip reading is easier and the teacher should face the child during all oral communication. Teachers should ensure there is good lighting so that visual aids can be clearly seen. Visual information as far as possible should be used to reinforce provided auditory information.

Teachers should not exaggerate pronunciation because this will deter understanding. Environmental noise should be kept to a minimum in order not to interfere with listening devices. Teachers should frequently check to ensure the listening devices are working properly. Sensitivity to the social, academic and emotional challenges faced by a child with hearing loss is also required.

Teachers should keep in mind that usually more than one visual thing is happening at one time, such as a teacher talking while expecting students to take notes of the lecture. It is not realistic, however, to expect a hearing-impaired student to read lips while also taking notes. The main notes could be provided to the student before the class so that he or she can focus on lip reading during the lecture. In the higher grades or university, where note-taking is done on a daily basis, volunteer note-takers can be assigned to help hearing-impaired children. Many hearing-impaired students will also need to take more work home to prepare for material to be covered in the next class.

Teachers are also advised to frequently check to ensure hard of hearing students understand information provided in class. When a student does not understand what is being said, the teacher can rephrase with additional words relevant to what he or she wants to say, thus providing cues to aid speech comprehension. Teachers should also use every opportunity to teach the other students about hearing loss and what can be done to support hearing-impaired children in class.

There are a number of instructional aids teachers can use when teaching deaf or hard of hearing students. A teacher can use sign, finger spelling and speech reading. Equipment, including overhead projectors, bulletin boards, computers and televisions showing captions on the screen, can also be used in teaching. Teachers can also use materials such as pictures, illustrations, artifacts, slides, computer graphics and films with captions. Visual aids including classroom rules charts, job and choice menus, transition time cards and charts, task organizers, daily schedules and the Internet can also be used to enhance the learning process and communication. Teachers can take a sensitive approach and alleviate unnecessary information that requires too much energy for the deaf or hard of hearing students to process.

\section{Conclusion and Recommendations}

The study has shown that students with hearing impairment do have severe challenges in the learning process at KG X Memorial school. Although the school was established to cater for the needs of all students enrolled be they normal students or those with hearing challenges, it is clear from the study that certain improvements have to be put in place in order to solve the challenges faced by hearing impaired students.

- There is need for schools to appoint a sign language interpreter in all schools where hearing impaired pupils are enrolled. Schools like King George IX Memorial also need to increase the number of teachers with sign language skills so that they can complement the other teachers who are not skilled in using sign language.

- Teachers who are not skilled in sign language, but teach hearing impaired students should be encouraged to get staff development courses on sign language. This will go a long way at equipping them with vital skills that will help them to teach hearing impaired students in their classes.

- Teachers need to develop empathy towards students with hearing impairment so that they design activities, and strategies that ensure that these students learn the subject under study.

- There is need for teachers to provide course outlines, lecture notes and handouts to interpreters who help the hearing impaired students so that they can go through the information in advance and where possible the learner can get help from parents and other helpers. Sign language interpreters can be allowed to view the course outlines, content, teachers' notes beforehand so as to interpret the information effectively to the students.

\section{References}

[1]. Al Qaryouti I. A. (2010) Inclusion of the disabled students in education. International Journal of Cross- Disciplinary in Special education (IJCDSE) VOL 1 (4) 216-222

[2]. Andrew J. (2000) The inclusive classroom: Educating exceptional children.(2 ${ }^{\text {nd }}$ edit.) USA Canadian publisher

[3]. Forman P. (2001) Integration and inclusion in Action. Baltimore Paul H Brook.

[4]. Lindsay G. (2007) "Educational psychology and the effectiveness of inclusive education" in Educational psychology Vol 77 Issue 1 $1-24$

[5]. Moore D. (1996) Educating the deaf. Boston Houghton Mifflin

[6]. Oyewumi A. (2008) An investigation on inclusive instructional practices and learning of students with hearing impairments in post secondary schools.

[7]. Mahwish S., Mahr M.S.A., Ghulan Fatima, Misbah M.2012) "Problems faced by students with hearing impairment in inclusive education" Journal of research and reflection in Education 129-136 